\title{
Different instructions during the ten-meter walking test determined significant increases in maximum gait speed in individuals with chronic hemiparesis
}

\section{Diferentes instruções durante teste de velocidade de marcha determinam aumento significativo na velocidade máxima de indivíduos com hemiparesia crônica}

Lucas R. Nascimento', Lívia C. G. Caetano², Daniele C. M. A. Freitas², Tatiane M. Morais², Janaine C. Polese', Luci F. Teixeira-Salmela'

\begin{abstract}
Objective: To evaluate the effects of different instructions for the assessment of maximum walking speed during the ten-meter walking test with chronic stroke subjects. Methods: Participants were instructed to walk under four experimental conditions: (1) comfortable speed, (2) maximum speed (simple verbal command), (3) maximum speed (modified verbal command-"catch a bus") and (4) maximum speed (verbal command + demonstration). Participants walked three times in each condition and the mean time to cover the intermediate 10 meters of a 14-meter corridor was registered to calculate the gait speed $(\mathrm{m} / \mathrm{s})$. Repeated-measures ANOVAs, followed by planned contrasts, were employed to investigate differences between the conditions ( $\alpha=5 \%$ ). Means, standard deviations and $95 \%$ confidence intervals (Cl) were calculated. Results: The mean values for the four conditions were: (1) $0.74 \mathrm{~m} / \mathrm{s}$; (2) $0.85 \mathrm{~m} / \mathrm{s}$; (3) $0.93 \mathrm{~m} / \mathrm{s}$; (4) $0.92 \mathrm{~m} / \mathrm{s}$, respectively, with significant differences between the conditions $(F=40.9 ; p<0.001)$. Comfortable speed was significantly slower than the maximum speed, indicating that the participants were able to increase speeds when required. Significant differences were observed between the second condition with the third $(p=0.002 ; 95 \% \mathrm{Cl}=-0.13$ to -0.03 ) and the fourth conditions ( $p=0.004 ; 95 \% \mathrm{Cl}=-0.12$ to -0.02$)$ with no differences between the third and fourth conditions ( $p=1.00$; $95 \% \mathrm{Cl}=-0.04$ to 0.05 ). Conclusions: The results indicated that simple verbal commands were not sufficient to capture maximum gait speed with chronic stroke subjects. Thus, for clinical assessments and research purposes, where measurements of the maximum gait speed are necessary, modified verbal commands or demonstration strategies could be employed by physical therapists to ensure acurate information.
\end{abstract}

Keywords: mobility; stroke; verbal reinforcement; physical therapy.

\section{Resumo}

Objetivo: Avaliar os efeitos de diferentes instruções para avaliação da velocidade de marcha máxima de indivíduos hemiparéticos durante o teste de caminhada de 10 metros. Métodos: Os indivíduos deambularam em quatro condições experimentais: (1) velocidade habitual, (2) velocidade máxima (comando verbal simples), (3) velocidade máxima (comando verbal modificado: pegar ônibus), (4) velocidade máxima (comando verbal + demonstração). Solicitou-se a cada participante que deambulasse três vezes em cada condição, e a média do tempo necessário para percorrer os 10 metros intermediários de um corredor de 14 metros foi utilizada para cálculo da velocidade (m/s). A ANOVA de medidas repetidas, com contrastes pré-planejados, foi utilizada para comparação dos dados $(\alpha=5 \%)$, sendo apresentados valores de média, desvio-padrão e intervalos de confiança (IC) de 95\%. Resultados: As médias de velocidade para as quatro condições foram: (1) $0,74 \mathrm{~m} / \mathrm{s}$; (2) $0,85 \mathrm{~m} / \mathrm{s}$; (3) $0,93 \mathrm{~m} / \mathrm{s}$; (4) $0,92 \mathrm{~m} / \mathrm{s}$, respectivamente, apresentando diferenças significativas entre as condições ( $F=40,9$; $p<0,001)$. A velocidade de marcha habitual diferiu das demais condições, indicando que os indivíduos foram capazes de aumentar a velocidade quando solicitados. Foram observadas diferenças significativas entre a segunda condição, a terceira $(p=0,002 ; \mathrm{IC} 95 \%=-0,13$ a $-0,03)$ e a quarta $(p=0,004 ; \mathrm{IC} 95 \%=-0,12$ a $-0,02)$, sendo que as duas últimas condições não diferiram entre si $(p=1,00 ; \mid \mathrm{IC} 95 \%=-0,04$ a 0,05). Conclusões: Os resultados indicaram que comandos verbais simples não foram suficientes para captar velocidade de marcha máxima em indivíduos com hemiparesia crônica. Assim, em situações em que seja necessária a avaliação de velocidade máxima, deve-se utilizar estratégia de comando verbal modificada ou associada à demonstração para garantir acurácia da informação.

Palavras-chave: mobilidade; acidente vascular encefálico; reforço verbal; fisioterapia.

Received: 06/15/2011 - Revised: 11/30/2011 - Accepted: 12/07/2011

${ }^{1}$ Physical Therapy Department, Universidade Federal de Minas Gerais (UFMG), Belo Horizonte, MG, Brazil 


\section{Introduction $: \because 8$}

Cerebrovascular accident (CVA) is described as a clinical syndrome due to a reduction of blood supply to brain structures and is considered one of the greatest public health problems and a major cause of disability in the world ${ }^{1-4}$. Although individuals after a CVA may show sensitive and cognitive impairments, the motor impairments which include muscular weakness, hypertonia, abnormal movement patterns and physical deconditioning are the most frequent ${ }^{5}$. Musculoskeletal disorders are considered important impairments in individuals with CVA and usually determine limitations in performing functional activities and activities of daily living, such as gait and stair ascent and descent ${ }^{2}$.

Individuals with hemiparesis commonly exhibit biomechanical gait changes. In general, they demonstrate decreased speed and cadence, prolonged swing phase, reduced range of motion, impaired balance and inability to transfer the weight into their paretic lower limb $b^{3,6,7}$. In addition, difficulties to change speed, direction, duration and intensity of muscular activity, resulting in uncoordinated motion of the paretic limb have also been described ${ }^{3,6}$.

Gait speed is a spatial-temporal parameter commonly deficient after a CVA and scientific evidence demonstrated considerable associations between this variable and those related to indicators of function and quality of life in this population ${ }^{8.9}$. Therefore, gait speed has been used as a reference for defining prognoses, levels of independence and efficacy of interventions ${ }^{8}$. Since it is a reliable, sensitive to changes and easy to apply, gait speed has been used in clinical ${ }^{3,6}$ and research settings ${ }^{10}$.

Although individuals suffering from a CVA demonstrate considerable difficulty in increasing gait speed, studies,11 have indicated that they are able to modify gait speed when requested or in certain daily life situations, such as running to reach a bus or picking up the phone. However, previous studies have evaluated comfortable and maximum gait speeds only using simple verbal command $d^{9,10,12-14}$, which is defined as a sequence of words directed from the therapist to the participant to obtain a motor specific response $\mathrm{e}^{15,16}$.

A simple verbal command can be a facilitator to enable the emergence of different motor behaviors and variations imposed by the tone of voice can directly influence motor responses ${ }^{17}$. In certain situations, a verbal component may not be enough to inform a patient of a particular set of desired responses ${ }^{15,17}$ and specifically, may not be able to properly target individuals with chronic hemiparesis to allow the emergence of the maximum gait speed supported by each patient's system. Thus, in order to improve the understanding of the provided instructions, it may be possible to add non-verbal components to the usual information ${ }^{15,18}$.
The association of other components to the traditional verbal components of tasks commands has been used to improve the performance of individuals during walking tests or during evaluations of the paretic upper limb. Guyatt et al. ${ }^{19}$ reported the effect of verbal encouragement commands during walking tests and found larger values of travelled distance when participants received verbal encouragement commands. Based on these results, they established specific guidelines for test performance. In evaluations of the paretic upper limb, in which the individuals should perform the proposed tasks in the shortest possible time ${ }^{20,21}$, the demonstration of the activity in maximum speed by the therapist has been shown to be an efficient method to assess individuals' capacity ${ }^{22}$. Although commands with additional information appeared to facilitate the understanding and optimize motor performance during task execution, studies which evaluated the effects of different instructions for the assessment of maximum gait speed in individuals with hemiparesis were not found.

Therefore, the objective of this study was to evaluate the effects of different instructions for the assessment of gait speed during the 10-meter walking test with individuals with chronic hemiparesis. The clinical questions were:

1. Can individuals with chronic hemiparesis increase their usual gait speed when requested?

2. Does the association of new instructional components to simple verbal commands determine significant increase in maximum gait speed?

3. Which instructional component associated with simple verbal commands determines the largest increases in maximum gait speed?

\section{Methods $: \because$.}

\section{Design}

An experimental study was conducted at the Motion Analysis Laboratory at the Universidade Federal de Minas Gerais (UFMG), Belo Horizonte, MG, Brazil. Individuals with chronic hemiparesis were recruited from the general community through advertisements were included, according the following criteria: (1) clinical diagnoses of unilateral CVA greater than six months of onset with associated hemiparesis of the lower limb; (2) age equal or above 20 years; (3) the ability to walk 14 meters independently; (4) absence of significant cognitive impairments which were identified by the Mini Mental State Exam (MMSE) ${ }^{23,24}$ and (5) the absence of any other neurological or orthopedic conditions not related to CVA. Individuals who were unable to understand or carry out the proposed tests were excluded from the study. All included participants 
provided consent, which was approved by the Ethics Research Committee of the UFMG, Belo Horizonte, MG, Brazil ( $n^{\circ}$. ETIC 0538.0.203.000-09).

\section{Instruments and measures}

Gait speed was evaluated by the 10-meter walking test, following the criteria described by Salbach et al. ${ }^{12}$. The test was performed on a flat 14-meter corridor, and the time required to cover the 10 intermediate meters was registered with a digital stopwatch, with the two initial and final meters being disregarded. Chairs were used to demonstrate the beginning and the end of the path to offer a visual target to the participants. The different instructions for the completion of the test were always provided by the same examiner and are described below.

\section{Procedures}

All participants took part in an initial assessment for clinical and demographic data and for the verification of the inclusion/exclusion criteria. Following this initial assessment, they were invited to perform the 10-meter walking test in four different experimental conditions being the last two randomized: (1) comfortable gait speed - participants were asked to walk in their comfortable and habitual speeds; (2) maximum gait speed (simple verbal command) - participants were requested to walk as fast as possible and safely, but without running; (3) maximum gait speed (modified verbal command: reach a bus) - participants received verbal command to walk as fast as possible and safely, but without running, to reach a bus which was about to pull out and (4) maximum gait speed (verbal command + demonstration) - participants were oriented to walk as fast as possible and safely, but without running, as previously shown by the therapist. Participants were oriented to walk three times in each specific condition, with 20 second rest intervals between each measurement. The time required to cover the intermediate 10 meters of the 14-meter corridor was recorded and further used to calculate gait speed $(\mathrm{m} / \mathrm{s})$. Mean speeds between the three performed trials in each condition were calculated.

\section{Statistical analyses}

Descriptive statistics were used for characterization purposes regarding the main clinical and anthropometric variables. Tests for normality (Shapiro-Wilk) and homogeneity of variance (Levene) were applied to all outcome variables. Based upon the normal data distribution, a multifactorial analysis of variance for repeated measures (ANOVA) followed by planned contrasts was employed to investigate differences between the evaluated conditions. All analyses were performed using the SPSS statistical program for Windows, version 15.0 with a significance level of $5 \%$. The results were shown as means, standard deviations and 95\% confidence intervals $(95 \% \mathrm{CI})$ for the comparison between the different experimental conditions.

\section{Results $: \because$ 。}

The sample included 14 individuals (10 men) with a mean age of $58 \pm 4.94$ years and time post CVA of $102 \pm 76.90$ months. Their clinical characteristics are described in Table 1.

The mean gait speed registered in each condition was: (1) comfortable speed: $0.74 \pm 0.23 \mathrm{~m} / \mathrm{s}$; (2) maximum speed (simple verbal command): $0.85 \pm 0.27 \mathrm{~m} / \mathrm{s}$; (3) maximum speed (modified verbal command: reach a bus): $0.93 \pm 0.30 \mathrm{~m} / \mathrm{s}$; (4) maximum speed (verbal command + demonstration): $0.92 \pm 0.30 \mathrm{~m} / \mathrm{s}$ ( $F=40.9$; $\mathrm{GL}=3 ; p<0.001$ ). Pre-planned contrasts revealed that the comfortable speed differed from the other conditions, indicating that the individuals were able to increase gait speed when requested ( $\mathrm{p}<0.001$; CI 95\% [-0.27 to -0.06$]$ ).

The simple verbal command demonstrated gait speed values significantly lower in relation to the modified command conditions, indicating that new instructions could be incorporated to the assessments of maximum gait speeds in individuals with chronic hemiparesis. The mean differences between conditions 2 and 3 were $0.08 \mathrm{~m} / \mathrm{s}$ ( $\mathrm{p}=0.002$; CI $95 \%$ [-0.13 to -0.03]) and between conditions 2 and 4 were $0.07 \mathrm{~m} / \mathrm{s}$ ( $p=0.004$; CI 95\% [-0.12 to -0.02]). No significant differences were observed between the two last conditions, indicating that both modified instructions could be used for the evaluation of maximum gait speed $(0.01 \mathrm{~m} / \mathrm{s} ; \mathrm{p}=1.000$; CI 95\% [-0.04 the 0.05]). The values obtained in each experimental condition are shown in Figure 1.

Table 1. Characteristics of the participants.

\begin{tabular}{lc}
\hline Outcome variable & Participants $(\mathrm{n}=14)$ \\
\hline Age (years), mean (SD) & $58(4.9)$ \\
\hline Gender, number of men (\%) & $10(71)$ \\
\hline MMSE (0-30), mean (SD) & $26.8(4.1)$ \\
\hline Side of hemiparesis, number of right (\%) & $6(43)$ \\
\hline Fulg-Meyer (0-34), mean (SD) & $22.5(5.2)$ \\
\hline Time since stroke (months), mean (SD) & $102(76.9)$ \\
\hline Tonus- Modified Ashworth Scale (0-4) & $1=36 \%$ \\
\hline & $1+=7 \%$ \\
\hline & $2=21 \%$ \\
\hline
\end{tabular}

SD=Standard deviation; MMSE=Mini Mental State Examination. 


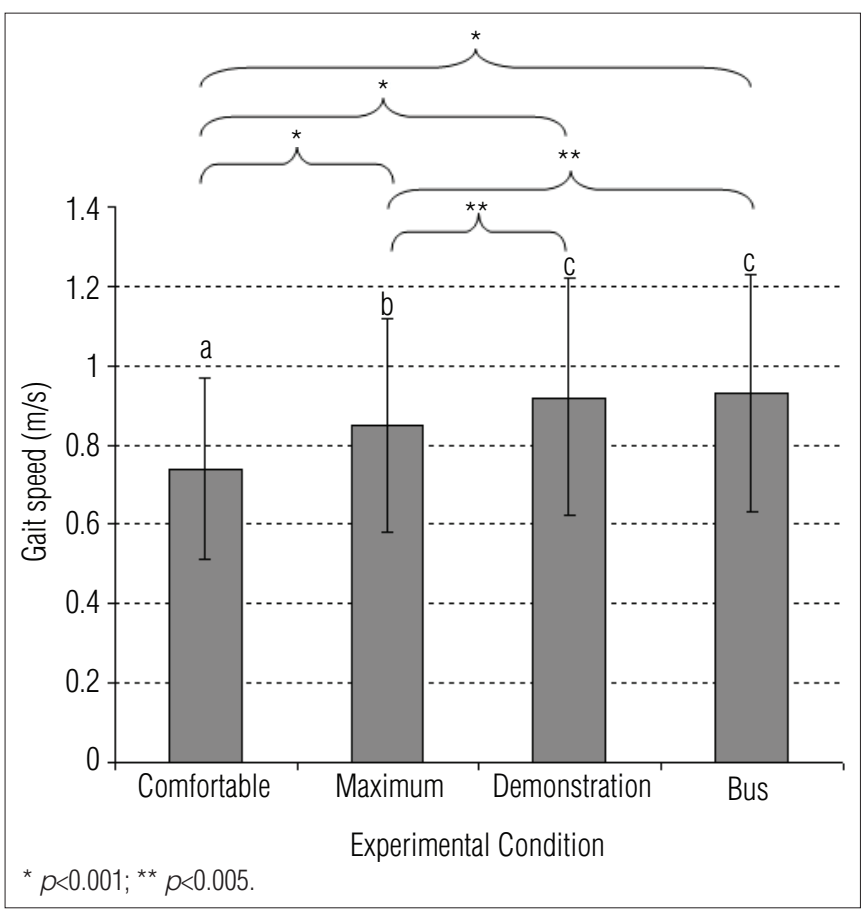

Figure 1. Mean and standard deviation of gait speed $(\mathrm{m} / \mathrm{s})$ for the four experimental conditions. For each column, different letters represent statistical significance between each condition.

\section{Discussion $: \because$.}

Measures of gait speed during short distances are often used as outcome measures in clinical practice and research to estimate the functional capacity and performance of individuals with $\mathrm{CVA}^{8,12,25}$. The clinical tests of gait speed are the most commonly administered and recommended for the evaluation of mobility of individuals post CVA, both in the community and in institutional settings, because they are easy to administrate, require no training or sophisticated equipments, and provide appropriate measures of mobility regarding the performance of daily living activities ${ }^{26,27}$. Furthermore, changes in gait speed are one of the main determining factors of functional improvements in this population and are significantly correlated with social and community performances of individuals with chronic hemiparesis ${ }^{26,28}$.

The results of this study indicated that individuals with chronic hemiparesis were able to increase their comfortable gait speeds when asked to, suggesting that this ability is used in daily life situations which require immediate acceleration, such as walking quickly to reach a bus or get a phone call. These findings reinforce the importance of clinical evaluation of maximum gait speed in addition to the comfortable one. According to Perry et al. ${ }^{8}$, from the maximum gait speed reached by these individuals, it is possible to estimate their levels of mobility and independence. For example, after three months of a CVA, the speed of $0.8 \mathrm{~m} / \mathrm{s}$ suggests independent gait; values around
$0.4 \mathrm{~m} / \mathrm{s}$ indicate restricted mobility within the community and of 0.26 to $0.4 \mathrm{~m} / \mathrm{s}$, mobility restricted to home ${ }^{8}$.

The maximum gait speed in this population is commonly evaluated by simple verbal commands provided by the therapist or the researcher during the test's instructions ${ }^{9-13}$. However, the non-employment of other incentive strategies to these simple verbal commands may underestimate the individuals' real capacities. The present findings indicated that the association of new instructional components to simple verbal commands determined significant increases in maximum gait speed. Thus, it is recommended that during clinical evaluations of maximum gait speed of individuals with chronic hemiparesis, the strategies of demonstration or modified verbal command (reach a bus) could be used to mimic the best performance of the individuals in their daily living situations.

Efforts have been made in an attempt to estimate the maximum gait speed in individuals with hemiparesis. Kollen, Kwakkel and Lindeman ${ }^{9}$ suggested that, in the population of individuals post CVA, the maximum gait speed is 1.3 times greater than the comfortable ones after controlling for time, age, time since CVA onset and type of intervention to which the individual had been submitted. There is a concern in submitting individuals with hemiparesis to consecutive evaluations of gait speed related to the number of repetitions of the test to obtain valid and reliable measures, especially in relation to the maximal speed tests, which could lead to overload or put subjects at risk ${ }^{29,30}$. In this study, the mean of three repetitions were chosen for analyses, but current evidence ${ }^{26}$ indicated that a single measure after a familiarization trial showed to be enough to capture real information concerning gait speed in clinical environment, without significant changes of the psychometric properties or measurement errors related to the evaluation. Thus, it is recommended, whenever possible, that clinical evaluations of maximum gait speed be performed instead of using estimates, because their use could provide different values for the actual gait speed. These findings reinforce the importance of establishing effective commands to allow the emergence of the maximum speed during the evaluations. The findings from this study showed that the use of the instructional modified components (reach a bus or demonstration) was able to determine significant increase in maximum gait speed of individuals with chronic hemiparesis, which was similar to the estimated values and facilitated the understanding and the specific actions of the activity.

Moreover, the results indicated important clinical implications related to gait training in this population, since it allows rehabilitation professionals to establish safe training goals in greater speeds, aiming for better preparation of individuals for the demands imposed by an independent lifestyle ${ }^{9}$. In 
individuals with hemiparesis, training at speeds closer to the actual ones can provide increase in gait speeds, changes in kinematics and muscular activation patterns which could reflect into better social adaptation and independent community ambulation ${ }^{11,31}$.

This study has some limitations related to the size and characteristics of the sample, which restrict the generalization of the results for the entire population of individuals with hemiparesis due to CVA. The findings from this study reflected the capacity of individuals with chronic hemiparesis with levels of motor recovery ranging between mild and moderate and without cognitive impairments. Therefore, future studies are needed to evaluate the effectiveness of the proposed commands for individuals in the acute phase or with more severe motor impairments. Other strategies may possibly be established for the evaluation of individuals with hemiparesis associated with cognitive impairments. Although the study provides information regarding the capacity of achieving maximum gait speed in a standardized research setting, other factors related to the natural characteristics of the environment could influence the performance of these individuals in their daily lives and should be investigated in future studies.

\section{Conclusions $\because \because$.}

The results of this study indicated that individuals with chronic hemiparesis were able to increase gait speeds when requested. However, simple verbal commands were not sufficient to capture maximum gait speed in this population. Based upon these findings, during clinical trials or scientific research in which assessment of maximum gait speed is required, the strategy of modified verbal command or command associated with demonstration should be used to ensure accurate information. The proposed commands will allow therapists to establish training goals in higher but safe speeds, for motor and functional recovery of individuals with chronic hemiparesis.

\section{Acknowledgment $: \because$.}

To the national funding agencies; Coordenação de Aperfeiçoamento de Pessoal de Nivel Superior (CAPES), Conselho Nacional de Desenvolvimento Científico e Tecnológico (CNPq) and to the Fundação de Amparo à Pesquisa do Estado de Minas Gerais (FAPEMIG).

\section{References $: \because$.}

1. Royall College of Physicans. National clinical guidilines for stroke. Intercollegiate Stroke Working. $2^{\mathrm{a}}$ ed. London; 2004

2. Teixeira-Salmela LF, Oliveira ESG, Santana EGS, Resende GP. Fortalecimento muscular e condicionamento físico em hemiplégicos. Acta Fisiátrica. 2000;7(3):108-18.

3. Richards CL, Olney S. Hemiparetic gait following stroke. Part II: Recovery and physical therapy. Gait Posture. 1996;4(2):149-62.

4. Minelli C, Fen LF, Minelli DP. Stroke incidence, prognosis, 30-day, and 1-year case fatality rates in Matão, Brazil: a population-based prospective study. Stroke. 2007;38(11):2906-11.

5. Martins EF, De Sousa PH, De Araújo Barbosa PH, De Menezes LT, Souza Costa A. A Brazilian experience to describe functioning and disability profiles provided by combined use of ICD and ICF in chronic stroke patients at home-care. Desabil Rehabil. 2011;33(21-22):2064-74.

6. Olney S, Richards C. Hemiparetic gait following stroke. Part I: Characteristics. Gait Posture. 1996;4(2):136-48

7. Trípoli F, Moreira SR, Oberg TD, Lima NMFV. Tarefas orientadas e biofeedback: efeitos na transferência de peso em hemiparéticos. Acta Fisiátrica. 2008;15(4):220-4.

8. Perry J, Garrett M, Gronley JK, Mulroy SJ. Classification of walking handicap in the stroke population. Stroke. 1995;26(6):982-9.

9. Kollen $B$, Kwakkel $G$, Lindeman $E$. hemiplegic gait after stroke: is measurement of maximum speed required? Arch Phys Med Rehabil. 2006;87(3):358-63

10. Dobkin BH, Plummer-D'Amato P, Elashoff R, Lee J; SIRROWS Group. Internacional randomized clinical trial, stroke inpatient rehabilitation with reinforcement of walking speed (SIRROWS), improves outcomes. Neurorehabil Neural Repair. 2010;24(3):235-42.

11. Lamontagne A, Fung J. Faster is better: implications for speed-intensive gait training after stroke. Stroke. 2004;35(11):2543-8.

12. Salbach NM, Mayo NF, Higgins J, Ahmed S, Finch LE, Richards CL. Responsiveness and predictability of gait speed and other disability measures in acute stroke. Arch Phys Med Rehabil. 2001;82(9):1204-12

13. Dean CM, Richards CL, Malouin F. Walking speed over 10 metres overestimates locomotor capacity after stroke. Clin Rehabil. 2001;15(4):415-21.
14. Duncan PW, Sullivan KJ, Behrman AL, Azen SP, Wu SS, Nadeau SE, et al. Protocol for the locomotor experience applied post-stroke (LEAPS) trial: a rondomized controlled trial. BMC Neurol. 2007;7:39

15. Galdino LACS, Varise EM. Os efeitos do comando verbal na reabilitação física. Rev Neurociênc 2010;18(1):95-102.

16. Cantagallo A, Spinazzola L, Rabuffetti M, Della Sala S. Verbal commands help the execution of endogenous movements in anarchic hand. Neuropsychol Rehabil. 2010;20(3):406-22.

17. Carr JH, Shepherd RB. The changing face of neurological rehabilitation. Rev Bras Fisioter 2006;10(2):147-56

18. Haguenauer M, Fargier P, Legreneur P, Dufour AB, Cogerino G, Begon M, et al. Short-term effects of using verbal instructions and demonstration at the beginning of learning a complex skill in figure skating. Percept Mot Skills. 2005;100(1):179-91.

19. Guyatt GH, Pugsley SO, Sullivan MJ, Thompson PJ, Berman L, Jones NL, et al. Effect of encouragement on walking test performance. Thorax. 1984;39(11):818-22.

20. Wolf SL, Catlin PA, Ellis M, Archer AL, Morgan B, Piacentino A. Assessing Wolf Motor Function Test as outcome measure for research in patients after stroke. Stroke. 2001;32(7):1635-9.

21. Faria-Fortini I, Michaelsen SM, Cassiano JG, Teixeira-Salmela LF. Upper extremity function in stroke subjects: relationships between the international classification of functioning, disability, and health domains. J Hand Ther. 2011;24(3):257-64.

22. Pereira ND, Michaelsen SM, Menezes IS, Ovando AC, Lima RCM, Teixeira-Salmela LF Confiabilidade da versão brasileira do Wolf Motor Function Test em adultos com hemiparesia. Rev Bras Fisioter. 2011;15(3):257-65.

23. Bertolucci PHF, Brucki SMD, Campacci SR, Juliano Y. O Mini-Exame do Estado Mental em uma população geral: impacto da escolaridade. Arq Neuropsiquiatr. 1994;52(1):1-7.

24. Brucki SMD, Nitrini R, Caramelli P, Bertolucci PHF, Okamoto IH. Sugestões para o uso do MiniExame do Estado Mental no Brasil. Arq Neuropsiquiatr. 2003;61(3B):777-81.

25. Browden MG, Balasubramanian CK, Behrman AL, Kautz SA. Validation of a speed-based classification system using quantitative measures of walking performance poststroke. Neurorehabil Neural Repair. 2008;22(6):672-5. 
26. Faria CD, Teixeira-Salmela LF, Neto MG, Rodrigues-de-Paula F. Performance-based tests in subjects with stroke: outcome scores, reliability and measurement errors. Clin Rehabil. 2011; [Epub ahead of print].

27. Jørgensen HS, Nakayama H, Raaschou HO, Olsen TS. Recovery of walking function in stroke patients: the Copenhagen Stroke Study. Arch Phys Med Rehabil. 1995;76(1):27-32.

28. Alzahrani M, Dean C, Ada L. Relationship between walking performance and types of community-based activities in people with stroke: an observational study. Rev Bras Fisioter. 2011;15(1):45-51.
29. Nadeau S, Arsenault AB, Gravel D, Bourbonnais D. Analysis of the clinical factors determining natural and maximal gait speeds in adults with a stroke. Am J Phys Med Rehabil. 1999;78(2):123-30.

30. Bohannon RW. Walking after stroke: comfortable versus maximum safe speed. Int J Rehabil Res. 1992;15(3):246-8.

31. Nascimento LR, Resende RA, Polese JC, Magalhães FAB, Teixeira-Salmela LF. Evidências sobre 0 efeito do fortalecimento muscular no desempenho motor e funcional de hemiparéticos crônicos: uma revisão sistemática. Ter Man. 2010;8(39):448-53. 